\title{
Proposta de ensino na EJA: \\ alguns sentidos dialógicos analisados à luz da teoria freiriana
}

\author{
Teaching proposal in the EJA: \\ some dialogical senses analyzed according Freirean theory
}

\author{
Propuesta de enseñanza en la EJA: \\ algunos sentidos dialógicos analizados a la luz de la teoría freiriana
}

\author{
Mariluci Almeida da Silva ${ }^{1}$ \\ https://orcid.org/0000-0002-2295-5735 \\ Janine Moreira ${ }^{2}$ \\ https://orcid.org/0000-0001-8421-277X
}

\begin{abstract}
Resumo: Este artigo decorre de uma pesquisa de mestrado em Educação, realizada em uma unidade de Ensino Fundamental da Educação de Jovens e Adultos (EJA), em Torres, cidade do Estado do Rio Grande do Sul. O objetivo geral desta pesquisa foi: "Compreender os significados do diálogo presentes no processo ensino-aprendizagem da Educação de Jovens e Adultos (EJA), à luz da concepção freiriana". A pesquisa foi qualitativa e, para o levantamento dos dados, contou-se com entrevistas semiestruturadas com professores, com equipes pedagógica e diretiva, como também, aplicação de questionários com alunos. A análise de dados se deu por categorias. O presente artigo apresenta a análise de três destas categorias: diálogo como respeito, diálogo como facilitador da vivência das boas relações, diálogo como forma de afetividade, assim como a análise de dados investigados no Regimento Escolar. O embasamento teórico foi, fundamentalmente, na pedagogia libertadora de Paulo Freire. Nas categorias supracitadas e no documento evidenciou-se "sentidos de diálogo" que ressaltam: o ato de saber escutar, o carinho, a amizade, a amorosidade, o respeito, a afetividade, a liberdade de expressão entre professores e estudantes para que haja a pronúncia e troca de experiências, sendo estes alguns dos subsídios convergentes para a concepção do diálogo em Freire.
\end{abstract}

Palavras-Chave: EJA. Sentidos de diálogo. Freire. Educação.

Abstract: This article is based on a Master's research in Education, carried out at elementary school unit of youth and adult education (EJA) in Torres, a city in the state of Rio Grande do Sul. The general objective of this research was: "Understanding meanings of the dialogue present in the teaching-learning process of Youth and Adult Education (EJA), according the Freirean conception". The research was qualitative and, data collection included semi-structured interviews with teachers, pedagogical and directive teams, as well as the application of questionnaires with students. Data analysis was by categories. This article presents the analysis of three

1 Orientadora Educacional do Instituto Federal Catarinense - Campus Santa Rosa do Sul.

E-mail: mariluciluis@gmail.com

2 Professora do curso de Psicologia e do Mestrado em Educação da Universidade do Extremo Sul Catarinense (UNESC) de Criciúma.

E-mail: jmo@unesc.net 
of these categories: dialogue as respect, dialogue as a facilitator of good relationships, dialogue as an affection form, also as the analysis of data investigated in the School Regiment. The theoretical basis was, fundamentally, in Paulo Freire's liberating pedagogy. In the aforementioned categories and in the document, the "senses of dialogue" have been highlighted and stand out: the act of knowing how to listen, care, friendship, love, respect, affection, freedom of speech between teachers and students so that there is the pronunciation and exchange of experiences. These are some of the convergent subsidies for the conception of the dialogue in Freire.

Keywords: EJA. Senses of dialogue. Freire. Education.

Resumén: Este artículo se deriva de una investigación de maestría en Educación, realizada en una unidad de Enseñanza Fundamental de la Educación de Jóvenes y Adultos (EJA), en Torres, ciudad del Estado de Rio Grande do Sul. El objetivo general de esta investigación fue: "Comprender los significados del diálogo presentes en el proceso enseñanza-aprendizaje de la Educación de Jóvenes y Adultos (EJA), a la luz de la concepción freiriana". La investigación fue cualitativa y, la obtención de los datos fue realizada a partir de entrevistas semiestructuradas con profesores, con equipos pedagógicos y directivos, como también, aplicación de cuestionarios con alumnos. El análisis de datos se dio por categorías. El presente artículo presenta el análisis de tres de estas categorías: diálogo como respeto, diálogo como facilitador de la vivencia de las buenas relaciones, diálogo como forma de afectividad, así como, el análisis de datos investigados en el Reglamento Escolar. El fundamento teórico fue, fundamentalmente, en la pedagogía liberadora de Paulo Freire. En las categorías arriba citadas y en el documento, se evidenció "sentidos de diálogo" que resaltan: el acto de saber escuchar, el cariño, la amistad, la amorosidad, el respeto, la afectividad, la libertad de expresión entre profesores y estudiantes para que haya la pronunciación y el intercambio de experiencias, siendo estos algunos de los subsidios convergentes para la concepción del diálogo en Freire.

Palabras clave: EJA. Sentidos de diálogo. Freire. Educación.

\section{INTRODUÇÃO}

Em cada momento histórico há desafios na busca da construção de sociedades que expressem uma vida digna para as pessoas. Na atualidade, esses desafios são enormes. O Brasil continua sendo o país com maior concentração de renda mundial. Este cenário requer uma série de políticas, em diferentes áreas, para sua superação. A educação é uma delas. Como alerta Paulo Freire, a educação sozinha não pode mudar o mundo, mas sem ela tampouco poderá haver transformação crítica da realidade. Cabe aos processos educativos, escolares ou não, possibilitar a capacidade e o desejo de busca por momentos reflexivos, nos quais possa haver a condução para a construção de novas perspectivas sociais. As autoras Guedes e Leitão (2016) nos trazem a contribuição de que:

[...] a educação - se colocada a serviço de processos de ensino e aprendizagem que favoreçam a reflexão crítica, criativa e dialógica do ser humano consigo mesmo e com o mundo - pode desempenhar papel importante no empoderamento dos sujeitos e na transformação de tal realidade. (GUEDES; LEITÃO, 2016, p.3).

O cenário brasileiro atual, ainda que não apenas atual, nos aponta uma problemática educacional a qual demanda uma necessidade urgente de ser reanalisada, rediscutida e redimensionada para a construção de uma sociedade voltada à participação de sujeitos au- 
tônomos, críticos e transformadores do meio em que vivem. E, acima de tudo, que estejam dispostos a participar de discussões reflexivas em prol da construção de um mundo mais justo e melhor, para a grande maioria da população. Mesmo tendo o entendimento de que essa transformação não acontece de um momento para outro, do dia para a noite, e no mesmo tempo em que almejamos que aconteça, mas sim a médio e longo prazos, temos o conhecimento de que as mudanças podem ocorrer, e no cenário educativo elas implicam na abertura de espaços para que o diálogo venha a ser desenvolvido no cotidiano das pessoas. Nesta luta por mudanças sociais, é necessário que os educadores e gestores em educação pensem com clareza a favor do quê e de quem, contra o quê e contra quem estão atuando, como sempre nos lembra Paulo Freire, indicando os interesses contraditórios próprios de sociedades cindidas em classes sociais. Precisamos de posicionamentos que demonstrem que não estamos simplesmente neste espaço terrestre por estar, mas sim, inseridos no mundo do qual fazemos parte, com o desejo de reconstruí-lo e, assim, torná-lo mais justo, especialmente para a maioria excluída: "[...] minha presença no mundo não é a de quem a ele se adapta mas a de quem nele se insere. É a posição de quem luta para não ser apenas objeto, mas sujeito também da História". (FREIRE,1996, p. 23).

Mas, ser sujeito da história implica em desalienar-se das condições que tornam as pessoas seus objetos. Os processos educativos que optam por esta justiça social necessitam ter clara a dificuldade de que pessoas transformadas em objeto possam se posicionar no sentido de quererem sair da condição de objeto em que vivem, para irem em busca de sua libertação. "A libertação, por isto, é um parto. E um parto doloroso. O homem que nasce deste parto é um homem novo que só é viável na e pela superação da contradição opressores-oprimidos, que é a libertação de todos" (FREIRE, 1987, p.19). Freire, no intuito de demarcar as diferentes posições dos indivíduos em uma sociedade dividida em classes sociais, identifica duas categorias: os opressores e os oprimidos. Os primeiros tratam a si mesmos como sujeitos, e os demais como objetos, visão esta que os oprimidos acabam internalizando e passa a ser sua própria visão de si. Para que o indivíduo deixe esta condição de ser objeto, há necessidade de desenvolver-se enquanto sujeito crítico, reflexivo e capaz de ter o entendimento de que a ação e a reflexão necessitam fazer parte das práticas do seu dia a dia, ou seja, da sua práxis. "[...] A práxis é este movimento de ação-reflexão-ação, em situação de pronúncia do mundo, tendo, portanto, o mundo como mediação" (MOREIRA, 2013, p. 48). Mas, para que isso aconteça, é indispensável a existência de espaços dialógicos, onde os participantes desses momentos tenham vez e voz para pronunciarem as suas experiências. Ao mudarem sua condição no mundo enquanto objetos, libertandose, os oprimidos acabam também possibilitando a libertação dos opressores, uma vez que tenham rompido com a relação desigual opressora. Mas, claro, somente se libertará dessa 
condição o opressor que, se dando conta do papel que desempenha no mundo, desejar transformar esta relação e, consequentemente, transformando a si mesmo.

Assim, Freire foi o educador que construiu sua concepção educativa tendo por base o diálogo entre diferentes - educador e educandos - mas não desiguais, ambos sujeitos na pronúncia do mundo, mundo que é a mediação para a passagem da consciência ingênua à consciência crítica.

Com a perspectiva de investigar a presença do diálogo na educação, em específico na modalidade de ensino da Educação de Jovens e Adultos (EJA), foi realizada uma pesquisa com estudantes e professores de uma escola pública estadual de ensino fundamental, localizada na cidade de Torres, no estado do Rio Grande do Sul. Este trabalho teve como objetivo geral: Compreender os significados do diálogo presentes na Educação de Jovens e Adultos (EJA), à luz da concepção freiriana.

Está sendo apresentada nesse texto uma parte dos dados empíricos, a partir de um questionário, respondido por 17 estudantes pertencentes às Totalidades de Ensino I, II, IV e VI da EJA, com idades entre 15 e 57 anos, e também dados vindos de entrevistas realizadas com 9 profissionais ( 5 professores, 2 membros da equipe gestora/diretiva e 2 da equipe pedagógica), os quais apresentavam no momento, tempo de experiência de trabalho na EJA entre 4 e 15 anos. Todas as respostas foram analisadas e classificadas em seis categorias, das quais três serão apresentadas neste artigo: Diálogo como respeito; Diálogo como facilitador da vivência das boas relações e Diálogo como forma de afetividade.

No decorrer da pesquisa, os profissionais foram identificados pelos seguintes códigos: Equipe Diretiva 1 (ED1), Equipe Diretiva 2 (ED2), Equipe Pedagógica (EPO) que significa Equipe Pedagógica de Orientação, Equipe Pedagógica (EPS) que representa Equipe Pedagógica de Supervisão, Professor de Religião e História (PRH), Professora de Artes (PA), Professora Alfabetizadora/Especial (PAE), Professora de Geografia (PG), Professora de Inglês (PI). Nem todas estas pessoas aparecem nos relatos de entrevistas deste artigo. As entrevistas foram gravadas e transcritas na íntegra, sendo apenas realizadas as correções ortográficas.

Os estudantes participantes desta investigação, cujas falas encontram-se descritas neste artigo, são reconhecidos pelos seguintes códigos: alunos da Totalidade 1 (T1 AM / T1 A); Totalidade 2 (T2 AF); Totalidade 4 (T4 B). As respostas transcritas dos questionários e citadas, também sofreram correções de linguagem. Estão descritas, ainda, informações encontradas no Regimento Escolar desta EJA, em relação às reuniões pedagógicas de capacitação, as 
quais ocorriam quinzenalmente entre professores, equipe pedagógica e equipe gestora. A análise dos dados relacionados a este documento fez-se presente como suporte para os dados levantados nas entrevistas, não havendo sua configuração de análise documental.

A seguir, é discorrido sobre a importância da trajetória da Educação de Jovens e Adultos, sendo ressaltada a Lei no 9.394/96, de 20 de dezembro de 1996, no que compete a esta modalidade de ensino; também são mencionadas as Conferências Internacionais de Educação de Adultos (CONFINTEAs I,II,III,IV, V e VI) e feita uma breve discussão sobre o cenário educacional atualmente vivenciado por profissionais e alunos da EJA. No item 3, partimos para as contribuições de Paulo Freire ao desenvolvimento de um ensino dialógico e libertador. No item 4, são apresentados alguns significados de diálogo encontrados na pesquisa, assim como informações relativas ao Regimento Escolar.

\section{ALGUNS PONTOS EM DISCUSSÃO SOBRE A EDUCAÇÃO DE JOVENS E ADUL- TOS (EJA)}

Uma das garantias de que as pessoas têm o direito de dar continuidade aos seus estudos escolares, quando não tiveram possibilidades de realizá-los na idade própria, é encontrada no texto da Lei $n^{\circ}$ 9.394/96, de 20 de dezembro de 1996, em seu artigo 37: "A educação de jovens e adultos será destinada àqueles que não tiveram acesso ou continuidade de estudos no ensino fundamental e médio na idade própria”. A lei enfatiza que tais estudos devem ser oferecidos visando qualidade no processo de ensino-aprendizagem. Se há a intenção de seguir a referida lei, e de ir em busca de uma educação de qualidade, faz-se necessário proporcionar aos educandos um ensino que possibilite a construção de uma trajetória escolar reflexiva e libertadora. Cortada (2013) nos apresenta a informação de que:

Numa visão abrangente, a função da Educação de Jovens e Adultos, muito mais do que a recuperação de um tempo de escolaridade perdido, é a de cumprir um papel emancipador e libertar o indivíduo-sujeito das limitações impostas pelo analfabetismo ou pela semialfabetização, facilitando-lhe o processo de escolhas e possibilitando a compreensão e a transformação da realidade. (CORTADA, 2013, p.7).

Faz-se necessário que este processo educativo possibilite aos educandos a compreensão de que a educação é um direito de todos. Que jamais deva ser interpretada como um favor que alguém está prestando ao sujeito que busca o conhecimento de forma institucionalizada, pois a partir do momento em que o ensino da modalidade EJA é visto e respeitado como direito, deve ser acompanhado por ações paralelas que demonstrem sua real importância e valorização, oportunizando, assim, um ensino que vá muito além das habilidades de ler, escrever e calcular. Educação esta que desenvolva seu trabalho numa linha reflexiva e 
comprometida com o direcionamento desses educandos, para uma leitura de mundo que os leve à compreensão do significado da participação de cada um na sociedade enquanto sujeito crítico, participativo e ético. Educação que busque possibilidades para despertar nesses sujeitos o desejo e a autonomia de fazer parte das decisões na sua comunidade, e no meio em que vivem, de forma atuante e prazerosa. Cury (2004) reforça que:

\begin{abstract}
A Educação de Jovens e Adultos não é um presente, nem um favor, tal como antes a própria legislação ou a prática das políticas educacionais a viam. [....] Por isso, a educação de jovens e adultos é um direito tão importante. Ela é tão valiosa que é uma condição prévia a muitas outras coisas de nossa sociedade: ler livros, entender cartazes, escrever cartas, sentar-se ao computador, navegar na rede mundial de computadores, votar com consciência, assinar o nome em registros, ler um manual de instruções, participar mais conscientemente de associações, partidos e desenvolver o poeta, ou o músico, ou o artista que reside em cada pessoa. Estes últimos aspectos, uma vez reparada a falta social de que tantos foram vítimas, devem ser encarados como o caminho mais qualificado para se falar em educação de jovens e de adultos. Trata-se do desenvolvimento das capacidades de cada um e o usufruto prazeroso delas. (CURY, 2004, p. 21 e 23).
\end{abstract}

Os estudantes que fazem parte da EJA, embora excluídos do sistema educacional regular, não são pessoas isentas de saberes, e estes são construídos em meio a suas vivências, as quais também conformam com suas subjetividades. Estas são manifestadas por suas sabedorias, evidenciadas por seu direito de pronunciar suas ideias, seus medos, suas ansiedades, suas limitações, os objetivos que desejam atingir e os que já foram atingidos. Enfim, a contribuição que esses estudantes trazem para a comunidade escolar, por intermédio da divulgação dos seus relatos de experiências, constituídos por suas culturas e seus saberes, enriquecem a bagagem de conhecimentos de todos que tiverem a oportunidade de fazer parte deste processo de ensino-aprendizagem. A presença deles na EJA está demarcada por sentimentos e pensamentos que vão muito além do ensejado pelos materiais escolares, que usam diariamente para realizar as atividades solicitadas por seus professores, e do espaço físico que ocupam dentro do ambiente escolar. Estes sentimentos e pensamentos ultrapassam os muros escolares, e se inscrevem nos locais em que diariamente escrevem as suas histórias de vida.

[...] não se pode desconsiderar que esses alunos jovens e adultos possuem uma grande bagagem de conhecimentos, construída ao longo de suas histórias de vida. Eles trazem consigo saberes, crenças e valores já constituídos, e é a partir do reconhecimento do valor de suas experiências de vida e de suas visões de mundo que cada aluno jovem ou adulto pode apropriar-se das aprendizagens escolares de modo crítico e original, na perspectiva de ampliar sua compreensão e seus meios de ação e interação no mundo. (SOARES; PEDROSO, 2013, p. 252).

O grupo de alunos da EJA é um público merecedor de todo o respeito da sociedade, devendo ser visto com um "olhar especial", no sentido de ser cumprido com seriedade e 
qualidade o seu direito de voltar a estudar. Que nesse ambiente de estudo possam dialogar com seus pares, tendo a oportunidade de proferir a sua palavra, sentindo-se, assim, incluídos no universo acadêmico. Direito esse, pertencente a todos os cidadãos.

Uma maior visibilidade e valorização em relação ao ensino da Educação de Jovens e Adultos começou a ser formada a nível nacional e internacional, a partir de Conferências Internacionais que se iniciaram no final da década de 1940. Em 1949, foi realizada a I Conferência Internacional de Educação de Adultos (I CONFINTEA), em Elsinore, na Dinamarca, com o objetivo de promover reflexões que levassem as pessoas a buscarem a paz, por ser um contexto de pós-guerra. A Il Conferência Internacional de Educação de Adultos foi promovida na cidade de Montreal, no Canadá, no ano de 1960. Teve como proposta principal direcionar um olhar especial para o acelerado crescimento econômico, proporcionando discussões sobre o papel dos Estados em relação à educação de adultos. A III Conferência Internacional de Educação de Adultos aconteceu na cidade de Tóquio, no Japão, em 1972, com os temas: Educação de Adultos e Alfabetização, momento em que foi enfatizada uma aprendizagem que fosse realizada no decorrer da vida, reforçando a importância de esforços para que houvesse o fortalecimento da democracia e a preparação para o enfrentamento, no sentido de diminuir o índice de analfabetismo mundialmente. A IV Conferência Internacional de Educação de Adultos aconteceu em Paris, em 1985, com a temática "Aprender é a chave do mundo". Nesse encontro foi significativa a importância de ser reconhecido o direito, sendo este o maior desafio para a humanidade, correspondente ao acesso dos recursos educacionais, buscando desenvolver: habilidades individuais e coletivas; aprender a ler e escrever; ter a liberdade para imaginar e criar; questionar e analisar; ler o próprio mundo e conseguir escrever sua história. No decorrer da mesma, também aconteceram discussões sobre as falhas das ações governamentais quanto ao não cumprimento do direito de milhares de cidadãos de terem um ensino adequado e com qualidade. A V Conferência Internacional de Educação de Adultos foi desenvolvida em Hamburgo, na Alemanha, no ano de 1997, cujo foco principal foi o tema da aprendizagem de adultos, como ferramenta para o exercício do direito, prazer e responsabilidade compartilhada. De acordo com os escritos de Paiva (2004), desde o acontecimento da referida conferência, a mudança na realidade educacional dos adultos analfabetos tornou-se um grande desafio a nível mundial.

Na Conferência de Hamburgo, especialmente, o sentido da educação de adultos alargou-se para absorver a ideia do aprender por toda a vida, como condição indispensável à vida adulta, porque os sujeitos se humanizam e se formam em processos continuados de aprendizagem, não representados necessariamente pela escola, mas pelos múltiplos espaços sociais em que interagem, como o do mundo do trabalho, das relações familiares, sociais, religiosas, de sindicatos, partidos políticos, associações etc. Metas foram estabelecidas e também foi reconhecido o direito de sujeitos jovens integrarem a modalidade educação de adultos, conforme 
vinha acontecendo, na prática educacional de muitos países do mundo, ao longo do intervalo de tempo entre as duas últimas conferências. (PAIVA, 2004, p. 4).

A VI Conferência Internacional de Educação de Adultos se deu em parceria com o Ministério da Educação do Brasil, sendo aqui realizada, organizada pelo Instituto da Unesco, na cidade de Belém, no Pará, no ano de 2009, no mês de dezembro. Esta conferência teve como tema: "Vivendo e aprendendo para um futuro viável: o poder da aprendizagem de adultos". Foi um grande desafio a favor da Educação de Jovens e Adultos, sendo a primeira a ser realizada em um país do hemisfério sul, ou seja, no espaço dos países chamados subdesenvolvidos, e onde se encontra a maioria dos adultos analfabetos do mundo. É relevante ressaltar que os objetivos em relação à educação de jovens e adultos nestes diferentes países podem ser distintos, pois o que vem a ser fundamental na progressão da aprendizagem ao longo da vida nos chamados países subdesenvolvidos, pode ser diferente dos países desenvolvidos. Por isso há a necessidade de salvaguardar discussões que partam da realidade de cada país, de acordo com suas necessidades.

Percebe-se, que ao longo da história educacional, houve transformação em relação às discussões voltadas para a modalidade de EJA, mas ainda se fazem necessários muitos outros momentos em que possam ser discutidos, além de aspectos gerais, com maior enfoque, as condições em que se encontram esses alunos em cada país, em cada estado, em cada região, em cada cidade, buscando, desta forma, a elaboração de um trabalho canalizado para a realidade em que vivem.

Dentre vários aspectos que precisam ser rediscutidos no ensino da EJA, podemos destacar a singularidade deste público em relação aos estudantes do ensino regular, pois trata-se de alunos adultos e também adolescentes, que necessitam afastar-se da estrutura educacional ofertada pelo ensino regular, por diversificados motivos. Uma parcela bastante significativa desses educandos só tem condições de regressar ao âmbito escolar após muitos anos de afastamento dos bancos escolares. A maior parte deles é constituída por trabalhadores, os quais trazem consigo uma grande bagagem de conhecimento de suas experiências vividas. Mas, até então, estavam em situação de marginalização e exclusão do processo educacional.

Desta forma, na elaboração e realização de um trabalho com educandos da EJA, o professor deve estar atento ao cuidado de não se direcionar a eles "como crianças", especialmente aos alunos que frequentam as turmas de alfabetização e pós alfabetização. Faz-se necessária a realização de um trabalho pedagógico que contemple a realidade dos alunos, na qual os conteúdos tenham ligação com o dia a dia desses trabalhadores. Mas também não se pode esquecer que vários estudantes são adolescentes, pertencentes às idades por volta de 
15, 16 e 17 anos, possivelmente apresentando objetivos de vida bastante diferenciados dos alunos adultos. Então, para que se tenha condições de atingir essa diversidade, o docente necessita atualizar-se, preparar-se constantemente. No entanto, sabemos que os professores, atualmente, encontram bastante dificuldade em participar de encontros de qualificação voltados para o trabalho com o público da EJA. São poucas as capacitações em que eles têm a possibilidade de participar. Eis aí um dos grandes impasses que perpassam a Educação de Jovens e Adultos: a formação de professores. "Um dos maiores problemas da EJA no momento atual é a falta de professores com formação específica na área para atender esse público diferenciado, de forma significativa e enriquecedora". (LISE; ANDREOLLA, 2014, p.59).

Um dos fatores que também demanda atenção é a inserção de estudantes na modalidade de ensino da EJA após completarem 15 anos, situação que vem acontecendo frequentemente com jovens que, após repetirem de ano, às vezes vão se sentindo desestimulados a continuarem no ensino regular, vindo a buscar na EJA outras alternativas de ensino, nas quais se sintam integrados e estimulados a prosseguirem em seus estudos. Também um dos motivos de os adolescentes estarem buscando a modalidade de ensino EJA pode estar associado às desigualdades sociais, pois são muitos os estudantes que necessitam trabalhar no período diurno para manter-se, ou então, para auxiliar suas famílias na renda familiar. "Crianças e jovens pertencentes às famílias de baixa renda têm necessidade de trabalhar desde cedo para manter-se ou contribuir para a renda familiar, o que dificulta, quando não impede, seu acesso, permanência e progresso na escola" (PAIVA et al, 2007, p.16). Também a taxa de distorção idade-série de estudantes tem sido bastante expressiva no sistema educacional brasileiro, especialmente no ensino médio. Nos escritos de Sampaio (2009), encontramos a seguinte informação:

A taxa de distorção idade-série do ensino médio, segundo dados do Censo Escolar 2005 , é de $46,3 \%$, o que indica que quase a metade dos alunos nesse nível de ensino tem idade superior à adequada à série frequentada. Este fenômeno contribui para as elevadas taxas de distorção da idade de conclusão deste nível de ensino, isto é, cerca de $40 \%$ dos concluintes do ensino médio têm idade superior a 17 anos. (SAMPAIO, 2009, p.8).

É importante destacar que no Brasil, ainda existem muitos municípios que não possuem estruturas escolares para oferecer os ensinos fundamental e médio completos. Principalmente em escolas rurais, inúmeros alunos, quando concluem o ensino fundamental, se obrigam a migrar para um outro centro escolar que, na maioria das vezes, encontra-se longe de suas comunidades, o que dificulta ainda mais a frequência nas aulas, favorecendo a repetência e a evasão escolar.

Mesmo sendo apresentadas tantas dificuldades no desenvolvimento da educação brasileira, destaca-se movimentos educacionais que têm se dedicado bastante para que $o$ 
cenário educacional tenha mais resultados positivos. Desses movimentos, cita-se os Encontros Nacionais de Educação de Adultos (ENEJAs), que vêm acontecendo anualmente desde 1999. Nesses encontros, têm sido elaborados registros de forma cuidadosa, através de relatórios finais realizados em cada encontro, ficando, desta forma, explicitados pensamentos, ideias, debates que proporcionam discussões, análises, diálogos que fazem, fizeram e farão parte da construção da história da educação.

No desenvolvimento deste trabalho pedagógico voltado para o ensino EJA, precisamos continuar recordando e refletindo sobre o fato de que este aluno traz consigo uma vivência construída por sua cultura, por aspectos de seu dia a dia na execução de seu trabalho, em seu lar, em sua comunidade, estando internalizados nesse sujeito muitos saberes, os quais poderão ser externados se houver um espaço que o incentive. Espaço que proporcione situações dialógicas embasadas no respeito ao desenvolvimento de atividades, e de ações que contribuam para que haja possibilidades de pronunciamento da palavra individual e grupal.

Sabemos que são muitos os obstáculos que assolam a educação. Mas, mesmo com tantas dificuldades encontradas, em qualquer enfoque educacional: nacional, internacional, estadual, regional, municipal, formal, informal, não somente na Educação de Adultos, mas no ensino regular, ou em qualquer nível educacional, jamais podemos deixar de persistir, de acreditar, de ter esperança de que a libertação dos seres humanos está interligada com a busca de novos conhecimentos, que os tornem pessoas com maior autonomia para tomar suas próprias decisões. Uma educação que possibilite o desenvolvimento do sentimento de capacidade, que os tornem encorajados e conscientes da importância que tem o ato de fazer parte da transformação de sua realidade, em busca de um mundo mais igualitário.

\section{CONTRIBUIÇÕES DE PAULO FREIRE PARA O DESENVOLVIMENTO DE UM EN- SINO DIALÓGICO E LIBERTADOR}

O pensamento freiriano nasce pela compreensão de Paulo Freire da urgência e necessidade de ser realizado um trabalho que desperte a consciência política das classes populares. Ações estas correspondentes ao Movimento Popular, e que viriam a transcender o espaço pedagógico. Na concepção freiriana, o homem só consegue realizar mudanças no mundo e transformá-lo, quando o pronuncia por intermédio do diálogo. Momento este em que se abre para proporcionar o entrelaçamento entre o amor, o respeito, a perseverança, a esperança de que acontecerá a humanização dos homens mediatizada pelo mundo. "O diálogo é este encontro dos homens, mediatizados pelo mundo, para pronunciá-lo, não se esgotando, portanto, na relação eu-tu" (FREIRE, 1987, p.45). 
A educação libertadora de Paulo Freire foi sendo construída a partir do entendimento de que a educação tem o compromisso ético-político de possibilitar a modificação da estrutura social, não somente como uma ação para o acúmulo de conhecimentos acadêmicos. Neste sentido, ela deve possibilitar a capacidade do educando de ver-se enquanto sujeito histórico, a partir de reflexões sobre sua vivência cotidiana, consubstanciada por seu trabaIho, por sua constituição familiar, por sua comunidade, todos estes elementos pertencentes à sua cultura. "O ponto de partida deste movimento está nos homens mesmos. Mas, como não há homens sem mundo, sem realidade, o movimento parte das relações homem-mundo" (FREIRE, 1987, p. 42). Desta forma, a direção da educação libertadora é o despertar do senso crítico do sujeito, levando-o à percepção de sua situação no mundo, possibilitando sua emersão das situações que o tornam objeto e não sujeito.

No processo educativo desenvolvido por Freire, a alfabetização não poderia ser realizada de forma mecânica, onde a "decoreba" e a reprodução dos conteúdos tenham papel principal. Este tipo de educação foi denominada por ele de "educação bancária". Paulo Freire, então, insiste na necessidade da existência de um ensino problematizador, no qual a escrita, a leitura, o ato de aprender e ensinar se constitua à guisa de um olhar libertador das condições de opressão do homem. Ensino que objetiva que os estudantes consigam se apropriar do seu direito de expressar as suas experiências por intermédio de sua palavra. Freire nos coloca que o movimento que impulsiona o ser humano a educar-se nasce de sua própria natureza de incompletude e inacabamento, é ontológico, e que o direciona constantemente ao interesse por novos conhecimentos. Ressalta-se, no entanto, a importância de um trabalho pedagógico que desperte nos educandos a curiosidade, sentimento este que os instigará à busca por novos conhecimentos, que os tirará da condição de ignorância, alienação, escravidão.

É na inconclusão do ser, que se sabe como tal, que se funda a educação como processo permanente. Mulheres e homens se tornam educáveis na medida em que se reconhecerem inacabados. Não foi a educação que fez mulheres e homens educáveis, mas a consciência de sua inconclusão é que gerou sua educabilidade. É também na inconclusão de que nos tornamos conscientes e que nos inserta no movimento permanente de procura que se alicerça a esperança. (FREIRE, 1996, p. 58).

A concepção epistemológica de Freire estrutura-se em uma epistemologia ${ }^{3}$ crítica, na qual o conhecimento é fruto de construções do sujeito em comunicação com a sociedade, com a cultura, com o mundo. Mediante esta busca por uma "educação problematizadora e reflexiva", oposta à "bancária", percebe-se que a educação tem um importante papel a cum-

3 O termo "epistemologia", de acordo com Michaelis (2017), significa: "conjunto de conhecimentos sobre a origem, a natureza, as etapas e os limites do conhecimento humano; teoria do conhecimento. Estudo crítico das premissas, das conclusões e dos métodos dos diferentes ramos do conhecimento científico, 
prir: o de participar na construção de uma sociedade mais justa e igualitária. $E$ isto se faz oportunizando aos educandos condições para o desenvolvimento da criticidade, alcançada por um trabalho de conscientização de seu papel ativo na história. Um ensino que se comprometa com a libertação dos vários tipos de opressão, vindo a ser orientado por princípios fundamentais como: amor, diálogo, respeito, humildade, bondade, solidariedade.

Diálogo em Freire (1987) é a oportunidade de expressão da pronúncia do mundo de cada um. A pronúncia do mundo implica em uma "ad-miração" do mundo. Em situação dialógica, eu me permito ouvir a "ad-miração" do mundo que o outro tem, e então posso "re-ad-mirar" este mesmo mundo, assim como o outro poderá fazê-lo em função da minha "ad-miração" dele. E assim, as pessoas poderão ir se aproximando dele, que é o mesmo para todos, mas significado por cada um de forma distinta. Esse acercamento ao mundo, a partir do mundo vivido de cada um, dado em situação coletiva, é a conscientização, ocasionada em situação de diálogo e possibilitadora da passagem da consciência ingênua para a consciência crítica. Porém, para que haja o diálogo é necessário ter "fé nos homens" - acreditar que todos têm a possibilidade de falar algo, de pronunciar o mundo, porque não há ninguém que "saiba tudo" ou que "ignore tudo". Esta crença no homem implica em amor à humanidade, amor consubstanciado no respeito por sua palavra, na fé em sua ação e na certeza da incompletude humana, de todos os homens, independentemente de sua classe social, raça, religião, gênero. Amor concretizado na ação transformadora para um mundo mais igualitário. Silva e Vasconcelos (2015) nos trazem a contribuição de que:

Na Educação Popular é de extrema relevância valorizar cada situação de forma particular, estabelecendo vínculos de partilha e cooperação, auxiliando e respeitando o educando, ouvindo suas expectativas com vistas à conquista de autonomia, numa contínua busca pela emancipação. (SILVA e VASCONSELOS, 2015, p.2).

A educação libertadora é a base da educação popular, educação voltada à emancipação das classes consideradas excluídas da sociedade, comprometida com a formação de sujeitos históricos, que se vejam possibilitados a agirem na sociedade, para transformá-la em um lugar de justiça social. É desta parcela excluída da população que chegam os alunos à modalidade EJA.

\section{ALGUNS SIGNIFICADOS DE DIÁLOGO ENCONTRADOS NA PESQUISA}

Neste item, refletiremos sobre alguns dados obtidos na pesquisa realizada com alunos e profissionais da modalidade de Ensino EJA, em uma escola de ensino fundamental,

das teorias e das práticas; teoria da ciência". Aurélio (2004) descreve o significado da palavra "epistemologia" como: "Estudo crítico dos princípios, hipóteses e resultados das ciências já constituídas; teoria da Ciência". 
situada na cidade de Torres, no estado do Rio grande do Sul. Lembramos que o objetivo geral da pesquisa foi: Compreender os significados do diálogo presentes na Educação de Jovens e Adultos (EJA), à luz da concepção freiriana.

Os significados do diálogo foram classificados em categorias. Neste artigo, apresentaremos as seguintes categorias: Diálogo como respeito; Diálogo como facilitador da vivência das boas relações e Diálogo como forma de afetividade.

Percebe-se uma pluralidade de entendimentos referente ao termo diálogo por parte dos participantes da pesquisa que frequentam o ambiente escolar da EJA da escola pesquisada. A diversidade dos significados identificados não apresenta nenhum distanciamento da valorização e importância da presença do diálogo dentro do ambiente escolar, muito pelo contrário, os variados adjetivos e interpretações a ele atribuídos enfatizam a amplitude de sua importância, quando presente no âmbito escolar onde se desenvolve o processo de ensino-aprendizagem. Uma das entrevistadas, identificada como EPS, salienta o quanto o diálogo vem a ser de extrema importância para o desenvolvimento do trabalho na Educação de Jovens e Adultos, sendo para ela inconcebível a ausência do mesmo.

"É quase que impossível tu conceberes a Educação de Jovens e Adultos sem o diálogo nas aulas, não existe. [...] sempre esta palavra é presente para o pessoal da EJA, não é uma palavra fora de seu contexto". (EPS).

Como demonstrado pela profissional acima, fica evidente a importância do diálogo entre professores e alunos da modalidade EJA. Apesar desse entendimento comum a respeito da valorização do diálogo, para os participantes da pesquisa o significado do termo é compreendido e interpretado de formas variadas. A partir delas foram pensadas as categorias já anunciadas, em um esforço de sistematização dos significados atribuídos ao termo "diálogo". O intuito desta pesquisa é que possa haver a contribuição de momentos reflexivos por parte desta equipe, onde aconteça a condução da busca por possibilidades, nas quais o diálogo seja um dos princípios essenciais da prática educativa. E que a ação dialógica seja um elemento da "práxis" desses sujeitos na Educação de Jovens e Adultos, objetivando a autonomia e libertação dos estudantes. Como citou Paulo Freire, na obra Pedagogia do Oprimido:

O diálogo não é um produto histórico, é a própria historicização. É ele, pois, o movimento constitutivo da consciência que, abrindo-se para a infinitude, vence intencionalmente as fronteiras da finitude e, incessantemente, busca reencontrar-se além de si mesma. (FREIRE, 1987, p.9).

Na sequência, foram analisadas as categorias elencadas anteriormente, de acordo com as respostas dos profissionais que compõem a equipe pedagógica/diretiva, dos pro- 
fessores e dos alunos participantes. Lembrando que o instrumento de pesquisa com os profissionais foi a entrevista e com os estudantes foi o questionário.

Iniciamos então, a apresentação de alguns dados evidenciados na pesquisa, com a categoria Diálogo como respeito.

Em relação aos alunos da EJA, ao observarmos as respostas utilizadas quando questionado o significado do termo diálogo, percebe-se que a expressão "respeito" é citada com certa regularidade, tornando-se um dos principais termos empregados por 5 estudantes. Não foram encontradas, nas entrevistas com os professores e equipe diretiva / pedagógica, falas que fossem pertinentes a esta categoria, por isso aparecem na mesma somente fragmentos de falas de alunos.

"O diálogo para mim é saber respeitar os outros, ter carinho, saber escutar as pessoas e ser honesto. O que facilita o diálogo é o grupo, que é unido, todos se ajudam e se respeitam". (T1 AM).

"Pra mim, a palavra diálogo significa ter carinho, respeito e fazer grandes amizades com outras pessoas". (T1 A).

"O que dificulta a vivência do diálogo é a falta de respeito, que muitas vezes, principalmente os jovens, não respeitam os professores e os colegas na sala de aula". (T4 B).

\footnotetext{
"Significa [...] ter respeito, educação. Cada um deve ter o seu tempo para ter um bom entendimento. Porque, às vezes, a maioria atropela um ao outro, não dando liberdade para se ter um bom esclarecimento. As pessoas devem ouvir mais e falar menos. A comunicação e o respeito têm que acontecer em todos os lugares". (T2 AF).

"Entre os colegas e professora, a gente tem bastante diálogo, convivência e respeito. Dou nota dez para o grupo que estou estudando, para mim parece uma família". (T2 A F).
}

As falas dos entrevistados T1 AM e T1A expressam que, para que aconteça o diálogo, além do respeito entre as pessoas, também é necessário que haja carinho, e desta forma, poderá surgir espaço para a construção de grandes amizades que possam se ajudar uns aos outros. Para o participante T4 B, a falta de respeito por parte dos jovens na sala de aula, tanto com colegas como com professores, acaba comprometendo o diálogo entre os membros do grupo, e assim, prejudicando o aprendizado dos conteúdos nas aulas. A participante T2 AF coloca que, para que haja diálogo, as pessoas precisam saber ouvir umas às outras, buscando falar menos e ouvir mais, para que assim, todos possam ter liberdade para conseguir esclarecer o que não entenderam e lhes ser proporcionada a oportunidade de um bom entendimento do que foi comunicado. E este respeito precisa acontecer em todos os lugares. Ela ainda coloca que se sente muito bem ao fazer parte 
do grupo de estudos em que está inserida, pelo fato de que entre eles há diálogo e respeito. O entendimento dos alunos em relação à necessidade de que haja respeito para que a comunicação aconteça entre as pessoas vai ao encontro da concepção freiriana. Pois, para Freire, o respeito é uma das virtudes de grande importância para que seja estabelecida uma relação dialógica através da qual haja a troca de experiências entre os sujeitos, proporcionando-Ihes condições para que se conscientizem de que, como seres humanos, possuem a capacidade de ser mais. "Somente nas práticas em que autoridade e liberdade se afirmam e se preservam enquanto elas mesmas, portanto no respeito mútuo, é que se pode falar de práticas disciplinadas como também em práticas favoráveis à vocação para o ser mais". (FREIRE, 1996, p.35). No entanto, os participantes não apresentam o entendimento freiriano do diálogo enquanto necessário para a conscientização, o entendimento do espaço de aula para dialógico para o acercamento gradativo à realidade.

Na sequência, apresentamos a categoria Diálogo como facilitador da vivência e de boas relações, com a análise de fragmentos de dois estudantes:

\footnotetext{
"Tem bastante diálogo, respeito, tanto com os colegas como com a professora. Facilita o diálogo a liberdade que os alunos têm em aula para expressar suas ideias. O bom relacionamento com a professora e os colegas". (T2 AF).

"A amizade facilita a vivência do diálogo, porque estamos aqui para aprender e ajudar os colegas que, às vezes, têm muita dificuldade em aprender". (T4 B).
}

Para os participantes relacionados acima, as boas relações proporcionam um espaço de convivência dialógica, baseada em aspectos como: respeito, boa comunicação dos professores com os alunos, liberdade de expressão de ideias em aula, proporcionada pelos professores, amizade entre os participantes do grupo, facilidade no desenvolvimento do aprendizado, construção de laços de amizade entre os participantes do grupo.

As expressões "respeito" e "liberdade" aparecem na fala do participante T2 AF, como colaboradores, para que o diálogo se estabeleça entre professores e alunos em aula. Este entendimento de diálogo aproxima-se da concepção freiriana, pois "liberdade e respeito" são princípios defendidos por Freire. "A concepção de liberdade, expressada por Paulo Freire, é a matriz que dá sentido a uma educação que não pode ser efetiva e eficaz senão na medida em que os educandos nela tomem parte de maneira livre e crítica" (FREIRE, 1979, p.27).

A fala do participante T4 B, ao ter expressado a importância de "aprender e ajudar os colegas", nos remete à ideia de solidariedade, de que o conhecimento deve ser difundido para que, desta forma, haja o acesso ao mesmo para muito mais pessoas, e não somente para uma parcela da população. Esse ato de solidariedade indica o início de uma constru- 
ção, que pode ser ampliada e disseminada de forma que venha a contribuir para a participação de grupos maiores de pessoas, e assim, sendo ampliada com a participação de muitas outras experiências que nascem do povo. Como demarca Freire: "esta busca do ser mais, porém, não pode realizar-se ao isolamento, no individualismo, mas na comunhão, na solidariedade dos existires [...]" (FREIRE,1987, p.43).

Seguindo ainda no contexto da categoria "Diálogo como facilitador da vivência e de boas relações", foi realizado um desdobramento dos fragmentos que resultaram na categoria intitulada como: "Diálogo como forma de afetividade". Freire nos coloca a amorosidade, que aqui podemos aproximar à afetividade, como o ato de comprometer-se com a realidade do outro, auxiliando-o na superação da referida realidade, proporcionando uma ética colaboradora com a busca de alternativas para superar as situações de desigualdades sociais, se posicionando contra a desumanização. Assim se estabelece um sentido de amorosidade com o próximo.

No projeto pedagógico e antropológico de Freire, o homem se torna liberto à medida que for capaz de ser autônomo, assumir a decisão pela mudança de si e da sociedade, através da educação permeada pela afetividade, pelo diálogo, pelo questionamento, pela conscientização oriunda de um processo comunitário, solidário e integrado de abordagem da realidade e do engajamento efetivo da mudança. (VECCHIA,2017, p.27)

Prosseguindo com a análise, serão apresentadas as falas de 4 profissionais, sendo eles 2 professores, 1 participante da equipe pedagógica e 1 participante da equipe diretiva. Nos questionários realizados com os alunos, não foram encontrados registros referentes a esta categoria, por este motivo, estão sendo explicitados somente fragmentos de professores, equipe diretiva/pedagógica.

"A gente trabalha muito com os professores, a todo momento, a todo tempo, a gente sempre reforça a questão da afetividade. Não tem como tu trabalhares na Educação de Jovens e Adultos se tu não estabeleces uma relação de afetividade com teu aluno. E, os nossos professores, a gente tem um grupo, de um modo geral, muito afetivo. É um grupo muito humano. Um grupo muito preocupado com o "ser". Então, é um grupo que facilita o nosso trabalho nesse sentido". (EPS).

"Se essa parte das relações humanas não for bem trabalhada, não acontece porque a gente não trabalha com máquinas, a gente trabalha com pessoas. Então, quando eu, profissional da área da educação, tenho alguma limitação, alguma dificuldade nessa questão mais de relação, do próprio diálogo, da afetividade, da aproximação, eu não consigo colocar em prática o que gostaria". (EPS).

"Quando nós [...] conhecemos e temos [...] um olhar sócio histórico para a realidade daquele sujeito, a relação de afetividade, ela propicia um maior diálogo". (PRH).

"A carência afetiva é assim... tu começas a conversar com eles. Já cansei de ver assim, alunos que chegam na supervisão e tu dizes: "- Ah, fulano, tá bonito hoje, 
né?" [...] Aí ele já senta, e começa a contar outras coisas. Então, tu vês que é bem a questão afetiva, a carência". (ED1).

"Acredito que só quando tu cativas e quando tu exerces uma amorosidade com os alunos e o professor é que se estabelece essa dialogicidade". (PI).

As falas dos participantes da pesquisa sobre afetividade estão manifestadas pela entrevistada (EPS) como necessidade de que seja trabalhado o tema "afetividade" com os professores, com a finalidade de que eles tenham um olhar mais afetivo ao desenvolver os trabalhos com o aluno em aula, e desta forma, buscar entendimento acerca da realidade do mesmo, para que, juntos, consigam estabelecer uma relação de diálogo que venha a contribuir com a troca de conhecimentos, e ambos sintam-se com liberdade de expressar suas experiências, buscando alternativas voltadas para uma educação mais humana. "Um educador humanista, revolucionário, não há de esperar esta possibilidade. Sua ação, identificando-se, desde logo, com a dos educandos, deve orientar-se no sentido da humanização de ambos" (FREIRE, 1987, p.35). Também foi colocado na fala da participante que os alunos da EJA, muitas vezes, possuem uma realidade na qual não há a vivência de momentos afetivos, e eles iniciam experiências afetivas no ambiente escolar da EJA.

O entrevistado PRH coloca a importância de o professor conhecer a realidade em que o aluno vive, para que a afetividade esteja presente em aula, entre professores e alunos. A entrevistada ED1 relata, como fator importante, os alunos serem instigados pelos profissionais que trabalham com eles a criarem estes laços de afetividade, por intermédio de momentos dialógicos que elevem a autoestima desses sujeitos. Talvez, nestes momentos, possam surgir oportunidades de que os mesmos venham a refletir sobre a importância de sua existência, buscando espaço para pronunciar suas experiências, que os elevem na crença de que é possível "ser mais". "A fé no homem é uma exigência primordial para o diálogo; 'o homem do diálogo' crê nos outros homens, mesmo antes de encontrar-se frente a frente com eles" (FREIRE, 1979, p. 43).

A participante PI fala da compreensão que tem de que a dialogicidade acontece somente quando o aluno é cativado, resultando daí um ambiente de amorosidade entre alunos e professores. Para ela, exercer a amorosidade e a afetividade fará parte dos momentos de trocas de experiências entre alunos e professores. Em Freire (1979), podemos encontrar a contribuição de que não há diálogo sem a existência de um verdadeiro amor que permeie entre os homens e o mundo. "O amor é ao mesmo tempo o fundamento do diálogo e o próprio diálogo" (FREIRE, 1979, p. 43).

O diálogo como afetividade, expresso pelos participantes da pesquisa, se direciona para uma educação humanizada, a partir de uma visão global do ser humano, e não de uma 
visão exclusivamente cognitiva. É uma visão importante, ainda que não expresse a intensidade da amorosidade freiriana, elemento necessário para que a capacidade humana seja desenvolvida com base na condição ética, na luta pela obtenção da valorização cultural e dos direitos de todos à igualdade social, havendo assim, a possibilidade da construção de uma sociedade mais justa e igualitária. No texto de Fernandes (2017), podemos encontrar a ratificação de que:

Freire trabalha com a concretude da produção do sentido e do sentir amorosidade/ amor como uma potencialidade e uma capacidade humana que remete a uma condição de finalidade existencial ético-cultural no mundo e com o mundo. Uma amorosidade partilhada que proporcione dignidade coletiva e utópicas esperanças em que a vida é referência para viver com justiça neste mundo. (FERNANDES, 2017, p. 37).

Ainda que a afetividade expressa pelos participantes da pesquisa não tenha a mesma abrangência que Freire dá à amorosidade, não conflitua com ela, chegando a ser uma facilitadora desta.

Estas três categorias apresentadas nos levam à reflexão de que, no ambiente escolar da EJA na escola pesquisada, há uma diversidade de entendimentos para o significado do termo "diálogo" por parte de alunos, professores, equipe pedagógica/diretiva. E que, dentre eles, ressalta-se o "sentido dialógico" contemplado por atitudes de: respeito, carinho, com o ato de saber escutar, a liberdade de expressão de experiências, a amizade, a afetividade, a amorosidade. Tais subsídios convergem para pontos de vista referentes ao diálogo em Freire, ainda que não o abarque na sua totalidade.

No entanto, não podemos deixar de ressaltar que, para que esse trabalho dialógico se desenvolva, são enfrentados grandes e inúmeros obstáculos, tanto por parte dos profissionais, como por parte dos alunos, pois ambas as partes vivenciam uma problemática que é proveniente de problemas sociais, políticos e econômicos, demonstrando, desta forma, o quanto as diferenças de classes sociais ainda continuam imperando na sociedade atual. Situações em que os indivíduos se sentem fragilizados, excluídos e, com isso, revoltados pelo fato de serem explorados e subtraídos em seus direitos de terem uma vida digna e justa. Observa-se indícios das dificuldades acima citadas nas falas abaixo, das participantes PAE e EPS:

\footnotetext{
"Muitas vezes há resistência de ambas as partes, professor e aluno. Em certos momentos do diálogo o aluno vem com atitudes agressivas por causa do seu histórico de vida, onde acontece o embate entre professor-aluno e aluno-aluno. As facilidades que eu percebo é quando eles conseguem estabelecer uma afetividade com professores e colegas, sua conduta melhora. Pois assim, os mesmos se sentem aceitos e amados". (PAE).
} 
"[...] ninguém dá aquilo que não tem. E, às vezes, os alunos são muito ríspidos, eles são agressivos, eles criam barreiras porque é o que eles conhecem da vida também. Eles não desenvolveram esta afetividade também, e às vezes, é aqui com a gente que eles começam a ter". (EPS).

As informações trazidas pelas participantes PAE e EPS reforçam, ainda mais, a necessidade de serem promovidos momentos dialógicos e reflexivos, não somente no espaço escolar, e com adolescentes ou adultos, mas sim com todas as pessoas, e com as diversas faixas etárias, para que, assim, possam todos os sujeitos terem a oportunidade de ter "vez e voz" para expressarem suas experiências, as quais fortaleçam as possibilidades para a transformação da realidade da qual fazem parte. "Educador e educandos (liderança e massas), [...] se encontram em uma tarefa em que ambos são sujeitos no ato, não só de desvelá-la e, assim, criticamente conhecê-la, mas também, no de re-criar este conhecimento". (FREIRE, 1987, p. 31).

\subsection{Regimento Escolar e reuniões pedagógicas da EJA}

Para que tenhamos um entendimento maior referente a esse documento conhecido como Regimento Escolar, e sobre a real importância dele como auxiliar no desempenho das atividades escolares administradas por educadores e educandos, se faz necessário nos munirmos de alguns conhecimentos essenciais sobre ele. Para isso, contamos com a contribuição de informações referentes ao Conselho Estadual de Educação do Rio Grande do Sul (CEE/RS).

No Regimento Escolar, devem estar explicitados com clareza, os objetivos que cada escola pretende desenvolver, pois é através deles que todos os sujeitos participantes do processo de ensino-aprendizagem terão conhecimento sobre os princípios, as concepções e as determinações institucionais. É de fundamental importância que a construção deste documento aconteça de acordo com a realidade de cada instituição de ensino, que tenha flexibilidade e que envolva toda a comunidade escolar. Como também, sua elaboração deve seguir orientações com suporte na legislação de ensino que estiver em vigor. A Resolução $n^{\circ} 236$, de 21 de janeiro de 1998, do CEE/RS, em seu Art. $1^{\circ}$, define Regimento Escolar como: "O Regimento Escolar é o documento que define a organização e o funcionamento do estabelecimento de ensino, quanto aos aspectos pedagógicos com base na legislação do ensino em vigor." (CEE/RG, 1998, p. 142).

Todos que fazem parte da comunidade escolar: professores, pais, alunos, colaboradores administrativos, equipe diretiva, equipe pedagógica, dentre outros, devem ter conhecimento do que consta no Regimento Escolar. É, inclusive, significativo que tal documento 
seja apresentado aos pais no início de cada ano letivo, já que ele é essencial para o bom desenvolvimento das atividades pedagógicas, pelo fato de ser orientador dos passos educativos do espaço pedagógico onde a comunidade encontra-se inserida. Na elaboração de um Regimento Escolar, percebe-se uma certa flexibilidade pelo fato de o documento poder ser construído de acordo com a autonomia e realidade de cada instituição escolar.

Ao pesquisar informações na organização curricular e metodológica da EJA em estudo, encontrou-se evidências de que há um espaço pedagógico reservado para que os professores e equipe pedagógica possam se reunir, e assim, proporcionar momentos dialógicos e participativos de encontros de formação pedagógica. "A proposta pedagógica, conforme o educando ao qual se destina - Jovens e Adultos [...] é desenvolvida em cinco turnos da semana, sendo que quinzenalmente, um turno é reservado à formação de professores, realizada através de reuniões, cursos ou encontros" (REGIMENTO ESCOLAR, 2017, p. 7).

Através da investigação sobre os encontros pedagógicos constatou-se, no que diz respeito às reuniões de professores e equipe pedagógica, que elas não estão somente descritas no documento, mas ocorrem na prática, seguindo um cronograma quinzenal, com a participação de professores, equipe diretiva e pedagógica. Nesses encontros, nota-se, a partir das entrevistas, que há esforço, por parte dos envolvidos, em dialogar sobre o processo de ensino-aprendizagem dos alunos, sobre os fatores que influenciam a vida das pessoas envolvidas, tanto de professores enquanto profissionais, como de alunos enquanto estudantes, e de ambas as partes como seres humanos. No Regimento Escolar da escola, no item que refere-se ao Plano de Trabalho do Professor, consta que "os educadores participam de encontros quinzenais objetivando a formação continuada necessária e constante para o trabalho com educandos de nossa escola" (REGIMENTO ESCOLAR, 2017, p. 12). Percebe-se que há preocupação, por parte dos professores, em buscar alternativas à concretização de um ensino de forma diferenciada, para que o aluno se motive na busca do conhecimento, acreditando em si mesmo, na realização dos seus sonhos, das metas que almeja alcançar para melhorar sua vida e a vida das pessoas que estão ao seu redor.

Na sequência, são apresentados trechos de entrevistas realizadas com as participantes ED2 e EPS que estão relacionados às reuniões acima citadas, entre professores, equipe diretiva e pedagógica.

"Sim, nós temos reuniões quinzenais. E ali, os professores colocam, relatam as experiências que tiveram, as angústias, as dificuldades. E a gente percebe na fala deles, aqueles que têm mais diálogo e aqueles que têm menos diálogo. Mas há o esforço em cada um de realmente fazer". (ED2). 
"A gente conversa muito, as nossas reuniões são de muita conversa, muito diálogo [...]. Muito um tentando ajudar o outro. A gente conversa sobre essas questões do outro, do afeto, dos rótulos, do nosso "aluno perfeito". (EPS).

"Semana passada, a gente teve reunião na escola e assistimos a uma fala do [Leandro] Karnal. E ele é muito incisivo nesta questão do professor ser o adulto da parada. Ele é muito direto nestas questões. Ele falou muito sobre a questão da arrogância do professor. Da arrogância intelectual. Que a gente tem que se despir disso também. A gente não pode ter a prepotência de achar que a nossa aula vai agradar, e vai ter a atenção de todos na turma. Porque nem sempre a tua aula vai realmente ser o mais importante na vida daquela pessoa. Principalmente quando tu estás falando de um adulto que veio do serviço, que veio cheio de problemas, que está cansado, que está passando por situações em casa". (EPS).

"[...] em cada reunião a gente leva uma história de vida dos alunos para [...] a cada reunião, a gente sempre procura resgatar. Você sabe o fulano? Você sabe qual é a história dele? E, os nossos professores é um grupo muito humano. Um grupo muito preocupado com o "ser". E é o que eu digo para os alunos, o professor é pessoa também. Então, as mesmas dificuldades que o professor tem com os alunos, com as características de cada um, eu supervisora, também tenho com os professores. Cada professor é um. Uns são mais afetivos, uns são mais maleáveis, outros não, até por uma situação de defesa do ser humano". (EPS).

Um espaço pedagógico planejado para a realização de reuniões de capacitação, com o intuito de que os profissionais possam falar sobre suas experiências, seus anseios, suas dúvidas, suas expectativas no sentido de fortalecerem suas ações pedagógicas, e juntos, buscarem alternativas para conseguirem oferecer aos alunos um trabalho de maior qualidade, é de fundamental importância para todos que fazem parte deste processo de construção.

No entanto, sabe-se que a construção do mesmo requer de cada participante dedicação, organização, paciência, persistência, participação e, acima de tudo, o desejo de exercitar o ato de saber o momento de expressar suas experiências, buscando respeitar o momento em que o outro tenha também o direito de pronunciar suas opiniões. E, desta forma, a reflexão tenha a oportunidade de estar presente em discussões que poderão ser direcionadas para ações pedagógicas que permeiem o processo ensino aprendizagem. Lembrando que as mudanças transformadoras não acontecem de um momento para outro, mas sim, a médio e a longo prazo. E que também faz parte deste processo um pensar e repensar constante, exigindo de cada um, e do grupo, a humildade de reconhecer que somos seres inacabados, e com isso, seres humanos constituídos de "erros e acertos", aspectos estes que poderão fazer a diferença no repensar a construção e reconstrução de novos rumos educacionais, pessoais, profissionais e, acima de tudo, sociais e humanos.

Mesmo com todas as dificuldades presentes no cotidiano escolar da EJA da escola pesquisada, percebe-se a preocupação da equipe pedagógica e diretiva em proporcionar um 
ambiente dialógico e reflexivo para que ambos, alunos e professores, sintam-se bem, e desta forma, consigam desenvolver um processo de ensino pedagógico baseado na realidade na qual a comunidade escolar está inserida. "O seu quefazer, ação e reflexão, não pode dar-se sem a ação e a reflexão dos outros, se seu compromisso é o da libertação" (FREIRE, 1987, p. 70). Esses encontros nos dão pistas de que os profissionais que fazem parte da modalidade de ensino EJA da escola em estudo se esforçam para estabelecer momentos dialógicos, o que converge na busca da essência do "ser mais", havendo maiores possibilidades de discussões fundamentadas nos sentimentos que constituem o ser humano, com valiosos momentos reflexivos, voltados para os problemas políticos, pedagógicos e sociais.

\section{CONSIDERAÇÕES FINAIS}

$\mathrm{O}$ ato de vivenciar, de construir e reconstruir, de pensar e repensar, de elaborar alternativas e caminhos para novas experiências faz parte da vida humana. E com isso, é instigada a curiosidade que move o ser humano, levando-o ao encontro de novos conhecimentos constantemente. Foi por intermédio do desejo de busca por conhecimentos atuais, voltados à verificação de como encontra-se a dialogicidade entre professores e alunos da EJA, que surgiu esta pesquisa. Durante a investigação, houve o direcionamento guiado pelo seguinte questionamento: Quais os significados da dialogicidade na Educação de Jovens e Adultos, à luz da concepção freiriana? Mantivemos nosso olhar e atenção para a dialogicidade com base na pedagogia libertadora, no entanto, a escola em estudo não a tem como referência em seus documentos, não precisando, portanto, estar comprometida com este referencial.

Neste artigo, foram analisadas as seguintes categorias: diálogo como respeito, diálogo como facilitador da vivência das boas relações, diálogo como forma de afetividade juntamente com dados investigados no Regimento Escolar.

Sabemos que a Educação de Jovens e Adultos é uma modalidade de ensino que, historicamente, passou por avanços, mas também por muitos retrocessos. O descaso por parte de gestões públicas se fez presente no passado, e ainda é evidenciado em nossos dias, o que explica algumas dificuldades que profissionais e alunos encontram para que seja desenvolvido um trabalho de qualidade na EJA. Podemos destacar, como um dos principais obstáculos, os poucos investimentos na formação dos profissionais, assim como a necessidade de construção de espaços educativos adequados ao público da EJA, ambientes estes que deveriam ter a identidade da Educação de Jovens e Adultos, e não simplesmente espaços emprestados, e às vezes, pouco adequados para os adultos. Essas são algumas condições adversas que são vivenciadas pelos participantes desta modalidade de ensino. Com esta in- 
vestigação, o que pudemos perceber é o quanto se faz necessário, por parte da gestão pública, um olhar especial para este público da EJA. Necessita-se da criação de políticas públicas que não fiquem elaboradas somente no papel, mas sim, colocadas em prática.

São inúmeros e importantes significados de diálogo que perpassam o âmbito escolar da Educação de Jovens e Adultos da escola pesquisada. Esses jovens e adultos que não conseguiram concluir seus estudos na idade própria para a obtenção do ensino regular não estão em busca de somente aprenderem a ler, escrever, calcular, interpretar. Acima de tudo, buscam o verdadeiro sentido de se reencontrarem consigo mesmos. De reconstruírem as histórias de suas vidas nos aspectos profissional e pessoal. Nutrem, por intermédio da persistência, da dedicação, da coragem de recomeçar, a esperança de que pode ser possível mudar o rumo de suas vidas e das pessoas que fazem parte do contexto de suas existências. Esses sujeitos têm muito a contribuir com suas experiências, mas para isso, precisam ser incentivados por intermédio de espaços, nos quais o diálogo seja utilizado como um dos principais instrumentos pedagógicos, buscando a possibilidade de compreensão de que todos devem ter o direito de expressar suas experiências. E que, para que a verdadeira práxis venha a acontecer, quanto ao processo de ação-reflexão-ação, é necessário o diálogo como ato reflexivo coletivo, para que a transformação seja efetiva e verdadeira. Lembrando que Paulo Freire nos fala da importância de pronunciarmos o mundo como sujeitos autônomos e capazes de refletir, de nos libertarmos da consciência ingênua para a consciência crítica, tornando-a libertadora.

Para este grupo de profissionais que desenvolvem o trabalho da EJA não falta ousadia, dedicação e boa vontade em querer transformar o meio em que trabalham, estudam e vivem, pois, em várias situações neste espaço de pesquisa, além do que já foi relatado, ressaltamos o amor que esses profissionais têm pelo que fazem. Fica aqui registrada uma fala da participante $\mathrm{PI}$, ao referir-se a um dos projetos desenvolvidos com os estudantes, o Projeto WORKSHOP, que partiu da seguinte pergunta: "E você, como profissional, por intermédio da mediação desta proposta de trabalho, que sentimentos Ihes são proporcionados?" E ela respondeu da seguinte forma: "São muitos sentimentos que se resumem em um só: AMOR PELO QUE SE FAZ". (PI). No grupo de profissionais e alunos que participaram do referido projeto, ficaram bastante evidentes: a dedicação, a ousadia, a autonomia, o desejo, e a boa vontade de fazer o ato pedagógico de forma diferente, buscando, desta forma, tentativas de transformar o meio em que exercem suas profissões, seus estudos e suas vivências diárias.

Destacamos a necessidade de os professores conseguirem participar de outras capacitações, além das que realizam quinzenalmente. Espaços os quais sejam preparados 
para que possam continuar exercendo um ensino de qualidade e de acordo com as faixas etárias dos alunos que frequentam essa modalidade de ensino, que vem a ser bastante diferenciada do ensino regular.

Todos os indivíduos merecem e têm direito a uma educação de qualidade, com possibilidades de se desenvolverem enquanto sujeitos autônomos, críticos e reflexivos, e assim, terem a oportunidade de fazer parte da construção de um mundo mais justo e igualitário, não somente para alguns, mas para todos os que dele fazem parte. No entanto, esta dívida é ainda maior para com aqueles que necessitaram, ou necessitam se ausentar do ambiente escolar, em sua infância e adolescência, sendo merecedores de todo o nosso respeito e consideração: os estudantes da EJA. Os dados desta pesquisa nos levaram a "inverter a seta": no lugar de vermos a EJA como o lócus "necessitado", aquela modalidade de ensino que parece estar "à margem", conseguimos enxergar o tanto que ela tem a ensinar aos demais níveis de ensino, incluindo o superior. Indo na direção freiriana de que todos sabem coisas, e da "fé no homem" - o que implica na humildade em reconhecer que todos podem ensinar e aprender -, fica o convite, no sentido de que vejamos a EJA como aquela que nos pode ensinar uma educação mais humanizada, que reconheça o contexto dos alunos, que valorize a afetividade, que proporcione o diálogo. É claro que nada disto se vivencia de forma harmônica, ao contrário, as vivências são permeadas por conflitos, por controvérsias, como é o movimento da vida. Portanto, encarar a EJA como tendo o que ensinar para outras modalidades de educação - incluindo-se a educação superior - seria um grande passo para andarmos mais certeiros na construção de uma educação que proporcione uma vida mais igualitária para todos.

\section{REFERÊNCIAS}

CORTADA, Silvana. A EJA, um território de compassos e descompassos. In: CORTADA, Silvana (Org.) EJA - Educação de Jovens e Adultos e seus Diferentes Contextos. Jundiaí: Paco Editorial, 2013. p. 7-39.

CURY, Carlos Roberto Jamil. Por uma nova Educação de Jovens e Adultos. In: TV Escola Salto para o futuro. Educação de Jovens e Adultos: continuar... e aprender por toda a vida. Boletim, set. 2004. Disponível em:< http://cdnbi.tvescola.org.br>. Acesso em 21 set. 2017.

FERNANDES, Cleoni. Amorosidade. In: STRECK, Danilo R; REDIN, Euclides; ZITKOSKI, Jaime José. (Orgs). Dicionário Paulo Freire. Belo Horizonte: Autêntica, 2017. P. 37 - 39. 
FERREIRA, Aurélio Buarque de Holanda. Miniaurélio: o minidicionário da língua portuguesa. 6.ed. Curitiba: Posigraf, 2004.

FREIRE, Paulo. Conscientização: teoria e prática da libertação uma introdução ao pensamento de Paulo Freire. São Paulo: Cortez \& Moraes, 1979.

. Pedagogia do Oprimido. 17. ed. Rio de Janeiro: Paz e Terra, 1987.

. Pedagogia da Autonomia: saberes necessários à prática educativa. 25 ed. São Paulo: Paz e Terra, 1996.

GUEDES, Marília Gabriela de Menezes; LEITÃO, Edineide Souza Sá. A contribuição da proposta educacional de Paulo Freire para a prática pedagógica docente na educação infantil e na educação de jovens e adultos. Revista e-Curriculum, São Paulo, v.14, n.1, p. 35 - 55 jan./mar.2016.

LISE, Luana; ANDREOLLA, Register. O "novo?" Sujeito da Educação de Jovens e Adultos: um diagnóstico necessário para uma intervenção pedagógica significativa. In: LAFFIN, Maria Hermínia Lage Fernandes (Org.). Educação de jovens, adultos e idosos na diversidade: processos de intervenção na realidade escolar e social. 1.ed. Florianópolis: Apoio, 2014.

MICHAELIS. Michaelis 2017: Dicionário Brasileiro da Língua Portuguesa. Ed. Melhoramentos. Disponível em http://michaelis.uol.com.br/moderno-portugues/busca/portugues-brasileiro/epistemologia/. Acesso em: 20 de nov. de 2017.

MOREIRA, Janine. Conscientização Freireana e Liberdade Sartreana: reflexões para os efeitos de subjetivação da educação popular. In: Flávio Brayner (Org.). Educação Popular: novas abordagens, novos combates, novas perspectivas. Recife: Ed. Universitária da UFPE, 2013. P.43-58.

PAIVA, Jane. Educação Jovens e Adultos: continuar... e aprender por toda a vida. TV Escola: Boletim Salto para o Futuro, Rio de Janeiro, setembro de 2004. Disponível em:< http:// cdnbi.tvescola.org.br>. Acesso em 21 de set. de 2017.

PAIVA, Jane; MACHADO, Maria Margarida; IRELAND, Timothy (Orgs). Educação de Jovens e Adultos: uma memória contemporânea, 1996 - 2004. Brasília: Secretaria de Educação Continuada, Alfabetização e Diversidade do Ministério da Educação: Organização das Nações Unidas para a Educação, a Ciência e a Cultura, 2007. (Coleção Educação Para Todos, v.1) Disponível em: < http://portal.mec.gov.br>. Acesso em 29 de set. de 2017.

RIO GRANDE DO SUL (Estado). Conselho Estadual de Educação. Coletânea de Leis, Decretos e Atos Normativos decorrentes da nova Lei de Diretrizes e Bases da Educação: Federal e Estadual. Porto Alegre.1998. 
SAMPAIO, Carlos Eduardo Moreno. Situação educacional dos jovens brasileiros na faixa etária de 15 a 17 anos. Brasília: Instituto Nacional de Estudos e Pesquisas Educacionais Anísio Teixeira, 2009. Disponível em: <http://inep.gov.br >. Acesso em 29 de set. de 2017.

SANTA CATARINA (Estado). Conselho Estadual de Educação RESOLUÇÃO № 182, de 19 de novembro de 2013. Lei no 4.394/69, que dispõe sobre o CEE/SC e, considerando o disposto na Lei $n^{\circ}$ 9.394/96, na Lei Complementar Estadual $n^{\circ} 170 / 98$, que dispõe sobre o Sistema Estadual de Educação. Florianópois.2013.

SILVA, Keila Mourana Marques; VASCONCELOS, Valéria Oliveira de. Ensinar e aprender sob o olhar de alunos da EJA: I: mediações da educação popular. In: $37^{a}$ REUNIÃO DA ANPED, 2015, Florianópolis.

SOARES, Leôncio José Gomes; PEDROSO, Ana Paula Ferreira. Dialogicidade e a formação de educadores na EJA: as contribuições de Paulo Freire. Educação Temática Digital, Campinas- SP, v.15, n. 2, p.250-263, maio/ago. 2013. ISSN 1676-2592

VECCHIA, Agostinho Mário Dalla. Afetividade. In: STRECK, Danilo R; REDIN, Euclides; ZITKOSKI, Jaime José. (Orgs). Dicionário Paulo Freire. Belo Horizonte: Autêntica, 2017. P. 26 - 27. 